0

George Fox

UNIVERSITY
Digital Commons @ George Fox University

Faculty Publications - Department of Health and Human Performance

Department of Health and Human Performance

2019

The Association between the Change in Directly Measured

Cardiorespiratory Fitness across Time and Mortality Risk

Mary T. Imboden

Matthew P. Harber

Mitchell H. Whaley

W. Holmes Finch

Derron L. Bishop

Follow this and additional works at: https://digitalcommons.georgefox.edu/hhp_fac

Part of the Medicine and Health Sciences Commons 


\title{
The Association between the Change in Directly Measured Cardiorespiratory Fitness across Time and Mortality Risk ir $^{2}$
}

\author{
Mary T. Imboden ${ }^{\mathrm{a}, 1}$, Matthew P. Harber ${ }^{\mathrm{a}}$, Mitchell H. Whaley ${ }^{\mathrm{a}}$, W. Holmes Finch ${ }^{\mathrm{a}}$, Derron L. Bishop ${ }^{\mathrm{b}}$, \\ Bradley S. Fleenor ${ }^{a}$, Leonard A. Kaminsky ${ }^{a, *}$ \\ a Ball State University, Muncie, IN, United States of America \\ ${ }^{\mathrm{b}}$ Indiana University School of Medicine, Muncie, IN, United States of America
}

\section{A R T I C L E I N F O}

\section{Keywords:}

Cardiopulmonary exercise testing

Risk reduction

Exercise training

Cancer

Cardiovascular disease

\begin{abstract}
A B S T R A C T
Background: The relationship between cardiorespiratory fitness (CRF) and mortality risk has typically been assessed using a single measurement, though some evidence suggests the change in CRF over time influences risk. This evidence is predominantly based on studies using estimated $\mathrm{CRF}\left(\mathrm{CRF}_{\mathrm{e}}\right)$. The strength of this relationship using change in directly measured CRF over time in apparently healthy men and women is not well understood.

Purpose: To examine the association of change in CRF over time, measured using cardiopulmonary exercise testing (CPX), with all-cause and disease-specific mortality and to compare baseline and subsequent CRF measurements as predictors of all-cause mortality.

Methods: Participants included 833 apparently healthy men and women ( $42.9 \pm 10.8$ years) who underwent two maximal CPXs, the second CPX being $\geq 1$ year following the baseline assessment (mean 8.6 years, range 1.0 to 40.3 years). Participants were followed for up to 17.7 (SD 11.8) years for all-cause-, cardiovascular disease(CVD), and cancer mortality. Cox-proportional hazard models were performed to determine the association between the change in CRF, computed as visit 1 (CPX1) peak oxygen consumption $\left(\mathrm{VO}_{2 \text { peak }}\left[\mathrm{mL} \cdot \mathrm{kg}^{-1} \cdot \mathrm{min}^{-1}\right]\right)$ visit $2(\mathrm{CPX} 2) \mathrm{VO}_{2 \text { peak, }}$, and mortality outcomes. A Wald-Chi square test of equality was used to compare the strength of $\mathrm{CPX} 1$ to $\mathrm{CPX} 2 \mathrm{VO}_{2 \text { peak }}$ in predicting mortality.

Results: During follow-up, 172 participants died. Overall, the change in CPX-CRF was inversely related to all-cause, CVD, and cancer mortality $\left(p<0.05\right.$ ). Each $1 \mathrm{~mL} \cdot \mathrm{kg}^{-1} \cdot \mathrm{min}^{-1}$ increase was associated with a $\sim 11,15$, and $16 \%$ (all $p<0.001$ ) reduction in all-cause, CVD, and cancer mortality, respectively. The inverse relationship between CRF and all-cause mortality was significant $(p<0.05)$ when men and women were examined independently, after adjusting for years since first CPX, baseline $\mathrm{VO}_{2 \text { peak, }}$, and age. Further, the Wald Chi-square test of equality found $\mathrm{CPX} 2 \mathrm{VO}_{2 \text { peak }}$ to be a significantly stronger predictor of all-cause mortality than $\mathrm{CPX} 1 \mathrm{VO}_{2 \text { peak }}(p<0.05)$.

Conclusion: The change in CRF over time was inversely related to mortality outcomes, and mortality was better predicted by CRF measured at subsequent test than CPX1 CRF. These findings emphasize the importance of adopting lifestyle behaviors that promote CRF, as well as support the need for routine assessment of CRF in clinical practice to better assess risk.
\end{abstract}

\section{Contents}

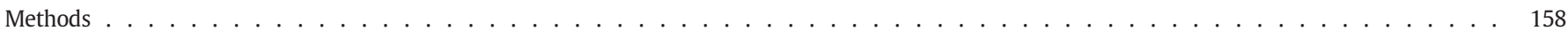

Resting health assessment $\ldots \ldots \ldots \ldots$

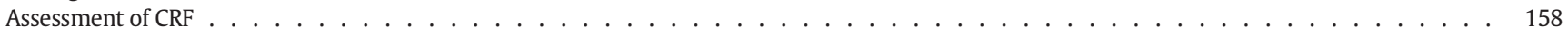

Abbreviations and Acronyms: ACLS, Aerobic Center Longitudinal Study; AHA, American Heart Association; ANOVA, analysis of variance; BALL ST, Ball State Adult fitness Longitudinal Lifestyle STudy; CI, confidence interval; CPX, cardiopulmonary exercise testing; CPX, CRF directly measured cardiorespiratory fitness obtained from cardiopulmonary exercise testing; $\bar{C}$ RF, cardiorespiratory fitness; $\mathrm{CRF}_{\mathrm{e}}$, estimated CRF; CVD, cardiovascular disease; HR, hazard ratio; ICD, International Classification of Diseases; MET, metabolic equivalent; NDI, National Death Index; $\mathrm{PA}$, physical activity; $\mathrm{VO}_{2 \text { peak, }}$ peak oxygen consumption.

is Statement of conflict of interest: see page 162 .

* Address reprint requests to Leonard A. Kaminsky, Ball State University, Fisher Institute of Health and Well-Being, 2000 University Avenue, Muncie, IN 47306.

E-mail address: kaminskyla@bsu.edu (L.A. Kaminsky).

${ }^{1}$ Current Affiliation: Mary T. Imboden, Ph.D. is currently an Assistant Professor at George Fox University. 


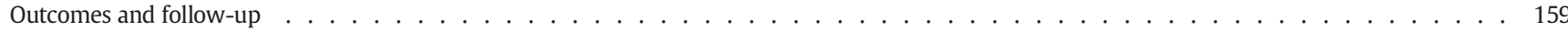

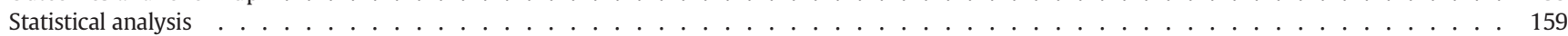

Results... . . . . . . . . . . . . . . . . . . . . . . . . . . . . . . . . . . . . . . 159

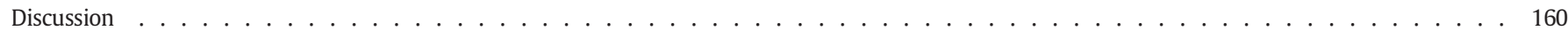

Strengths and limitations . . . . . . . . . . . . . . . . . . . . . . . . . . . . . . . . . . . . . . . . . . . . . . . . . . . . 161

Conclusion . . . . . . . . . . . . . . . . . . . . . . . . . . . . . . . . . . 162

Statement of conflict of interest . . . . . . . . . . . . . . . . . . . . . . . . . . . . . . . . . . . . . . . 162

Financial support, funding, grants . . . . . . . . . . . . . . . . . . . . . . . . . . . . . . . . . . . . . . . . 162

Acknowledgments . . . . . . . . . . . . . . . . . . . . . . . . . . . . . . . . . . . . . 162

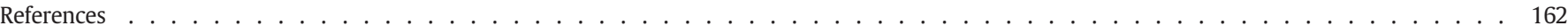

Healthy lifestyles are gaining increased recognition in clinical and public health settings. ${ }^{1,2}$ Cardiorespiratory fitness (CRF) is a key outcome measure associated with healthy lifestyles. Evidence has consistently shown CRF to be a strong and independent predictor of chronic disease, including CVD, cancer, and all-cause mortality. ${ }^{3-7}$ Several studies have shown CRF to be a better predictor of health outcomes in both healthy and clinical populations than traditional cardiovascular disease (CVD) risk factors that are commonly assessed clinically., ${ }^{4,5}$

CRF is a modifiable risk factor that is influenced by lifestyle and health parameters, including exercise training status. ${ }^{8-11}$ Improvements in CRF have been shown to result in beneficial changes in traditional risk factors and health. ${ }^{12-14}$ Additionally, there is growing evidence suggesting changes in estimated $\mathrm{CRF}\left(\mathrm{CRF}_{\mathrm{e}}\right)$ over time ( $>1$ year), are associated with changes in mortality risk. ${ }^{15-21}$ Since CRF may change over time, the routine assessment of CRF may have stronger prognostic value and use as a mortality risk assessment tool than a single CRF measurement.

Past studies assessing the association between the change in CRF over time and mortality have predominately used $\mathrm{CRF}_{\mathrm{e}}$ from exercise test workload or duration. ${ }^{4,15-17,19-21}$ Additionally, past studies have only assessed men and used cohort specific reference values to define CRF thresholds. ${ }^{415-17,19,21}$ These factors may limit the generalizability of the findings and clear understanding of this relationship. ${ }^{22,23}$ Further, the estimation errors associated with $\mathrm{CRF}_{\mathrm{e}}$ may impact an individual's risk assessment, reducing its sensitivity.

Recent scientific statements and reviews have emphasized the need for more studies assessing the association between directly measured CRF, obtained from cardiopulmonary exercise testing (CPX-CRF) which is considered the gold standard method, and mortality outcomes. ${ }^{24,25}$ Only two studies have used CPX-CRF as a baseline measure and only one study has examined the association between the change in CPXCRF and mortality apparently healthy individuals. ${ }^{3,15}$ Laukkanen et al. studied 579 men (age range: 42-60 y) from eastern Finland who performed two CPX with cycle ergometry 11-years apart. ${ }^{15}$ After a median follow-up of 13.3 years from the second CPX, a graded relationship was found, where each 1 MET higher change was associated with a $30 \%$ lower risk of all-cause mortality. The findings from this study of middleaged Finnish men tested using a cycle ergometer protocol may not be generalizable to other populations, including women, nor to CPX-CRF measured using treadmill as the mode for testing. Therefore, the primary aim of this study was to examine the association of the change in CPX-CRF over time ( $>1$ year between CRF measures) with all-cause and diseasespecific mortality in a cohort of apparently healthy men and women. Secondly, this study sought to determine if a second measure of CRF, > 1 year after the first, improves the prediction of mortality risk across time above a single measure.

\section{Methods}

The study cohort included 833 apparently healthy participants (552 men, 281 women; baseline mean age: $42.9 \pm 10.8$, range 18.082.0 years) obtained from the Ball State Adult fitness Longitudinal Lifestyle STudy (BALL ST) cohort. Participants were self-referred either to the Ball State University-Adult Physical Fitness Program, a communitybased exercise program or were research subjects in clinical exercise physiology related studies who gave written informed consent for their data to be used for research. Participants were considered apparently healthy, as all were free from known CVD (history of cardiac arrest, coronary artery disease, heart failure, myocardial infarction, and stroke) and cancer at baseline or follow-up. CVD diagnosis was self-reported and verified by written physician confirmation. All participants completed two health and fitness assessments between 1969 and 2017, each including a CPX achieving a peak effort criteria of a respiratory exchange ratio $\geq 1.0$ during both $\mathrm{CPX} 1$ and $\mathrm{CPX} 2$. These two exams were $\geq 1$ year apart (mean 8.6 years, range 1.0 to 40.3 years). This study was reviewed by the Ball State University Institutional Review Board and determined exempt as only de-identified data were used.

\section{Resting health assessment}

A full description of the procedures involved in the resting health and fitness measurements performed prior to both CPXs have been explained previously. ${ }^{26,27}$ In summary, participants completed a health history questionnaire, providing demographic information, personal and family medical history, medication usage, and lifestyle behaviors. Information gained from the questionnaire was used to screen for medical contraindications and/or physical limitations to CPX.

Lifestyle behaviors of physical activity (PA) and smoking were selfreported. PA status was classified as inactive or active, with active being designated if participants reported engagement in regular PA, meeting the US aerobic PA guidelines for adults. ${ }^{28}$ Smoking status was categorized as current smoker, including those that used cigarettes or quit within the past year, or a non-smoker at CPX1.

Clinical measurements including, resting heart rate, blood pressure, anthropometrics (height, weight, waist circumference), 12-lead electrocardiogram, and blood chemistry ( $\geq 8 \mathrm{~h}$ post-prandial), were performed by trained technicians using standardized laboratory procedures. These measurements were used to determine the presence of risk factors, including obesity, hypertension, dyslipidemia, and impaired fasting glucose, defined according to current accepted atherosclerotic CVD risk factor criteria. ${ }^{29}$

\section{Assessment of CRF}

A more thorough description of the procedures used to assess CRF have been described previously. ${ }^{3,26}$ In summary, at visit one CPX was performed using a standardized treadmill or cycle protocol, to determine peak oxygen consumption $\left(\mathrm{VO}_{2 \text { peak }}\right)$. The mode of exercise was chosen based on participant preference, comfort, and the presence of functional limitations as determined through the health history questionnaire. Standardized procedures were followed for metabolic cart calibration and all CPXs were supervised by trained clinical exercise physiologists, with additional medical supervision when appropriate. ${ }^{30}$ Participants were encouraged to exercise to volitional fatigue and a respiratory exchange ratio $\geq 1.0$ was used as an objective indicator of maximal effort. 
All participants were re-tested in the Clinical Exercise Physiology laboratory $\geq 1$ year after their baseline assessment. At this second assessment, both CPX-CRF and resting health and fitness measurements were reassessed following the same standardized procedures and criteria as at baseline. CPX2 was also performed using the same mode of exercise as at CPX1.

\section{Outcomes and follow-up}

All participants were followed from the date of their CPX2 through 2017 or until date of death for all-cause mortality or December 31, 2016 for disease-specific mortality. The National Death Index (NDI) was the primary data source for obtaining vital status between 1979 and 2016, providing date of death and cause of death. There were no deaths reported in the cohort prior to 1979. Deaths occurring after 2016 ( $n=10$ ) were confirmed by obituary review. The underlying cause of death determined from the NDI report was coded according to the International Classification of Diseases (ICD), 9th revision, prior to 1999 and the ICD, 10th revision, from 1999 to $2016 .{ }^{31,32}$ CVD mortality was defined by the ICD, 9th revision codes 390.0 to 449.9 and ICD, 10 th revision codes I00.0 to I78.9. Cancer mortality was defined by the ICD, 9th revision codes 140.0 to 239.0 and ICD, 10th revision codes C00.0 to D49.9. For all other ICD codes, cause of death was classified as other.

\section{Statistical analysis}

SPSS V. 24 (SPSS, Inc., Chicago, IL) and SAS V. 9.3, were used for all statistical analyses. Descriptive statistics were performed to summarize characteristics of the cohort and a univariate analysis of variance (ANOVA) and chi-square goodness of fit test were used when appropriate to test for significant differences between sexes and vital status (living vs. deceased). Paired $t$-tests were used to assess the differences between resting health and fitness and CPX measurements. To determine significant differences between CPX1 and CPX2 measures, all descriptive data were normalized to account for differences in the number of years between subject's CPXs. Cox proportional hazard models were used to determine hazard ratios (HR) and 95\% confidence intervals $(\mathrm{CI})$ associated with the change in CRF as related to all-cause, CVD, and cancer mortality. Sex-specific hazard models were used to determine the HR related to all-cause mortality according to change in CRF. There were an inadequate number of cases of CVD and cancer specific mortality for sex-specific analyses. CRF was expressed as $\mathrm{VO}_{2 \text { peak }}$ in $\mathrm{mL} \cdot \mathrm{kg}^{-1} \cdot \mathrm{min}^{-1}$ and the continuous change in CRF was computed as the difference in $\mathrm{VO}_{2 \text { peak }}$ between $\mathrm{CPX} 1$ and $\mathrm{CPX} 2$. The Cox proportional hazard models were fit to the data and run adjusted for years between CPXs (model 1), additionally controlled for $\mathrm{CPX} 1 \mathrm{VO}_{2 \text { peak, age, and sex }}$ (model 2), and then with further adjustment for the change in traditional CVD risk factors (model 3; dyslipidemia, hypertension, impaired fasting glucose, obesity, physical inactivity and smoking status), which were categorized by the change in each risk factor status between CPX1 and CPX2. The Cox models were obtained separately on a subgroup of the cohort with $\geq 5$ years $(n=491)$ between CPXs to determine if the relationship remained consistent. A Wald Chi-square test was used to compare the coefficients estimating the relationship of CPX1 CRF to CPX2 CRF with time until death for all-cause mortality. These models were obtained both unadjusted, and then adjusted for years between CPXs, age, and sex.

\section{Results}

Table 1 provides descriptive characteristics of the study cohort at CPX1. Men had a higher absolute CRF than women, however, there were no differences in their values based on age and sex specific reference standards. Additionally, men had a less favorable risk factor profile
Table 1

Descriptive characteristics of the BALL ST Cohort at CPX1.

\begin{tabular}{lll}
\hline & Men $(n=552)$ & Women $(n=281)$ \\
\hline Age $($ years $)$ & $44.6 \pm 9.8$ & $45.0 \pm 10.8$ \\
$\mathrm{VO}_{\text {2peak }}\left(\mathrm{mL} \cdot \mathrm{kg}^{-1} \cdot \mathrm{min}^{-1}\right)$ & $36.6 \pm 9.3^{*}$ & $27.8 \pm 7.3$ \\
$\mathrm{VO}_{\text {2peak }}\left(\mathrm{L} \cdot \mathrm{min}^{-1}\right)$ & $3.10 \pm 0.03^{*}$ & $1.90 \pm 0.04$ \\
$\mathrm{METs}$ & $10.8 \pm 2.7^{*}$ & $8.3 \pm 2.2$ \\
FRIEND percentile & $46 \pm 26$ & $54 \pm 25$ \\
Weight $(\mathrm{kg})$ & $87.2 \pm 16.8^{*}$ & $69.5 \pm 14.6$ \\
BMI $\left(\mathrm{kg} \cdot \mathrm{m}^{-2}\right)$ & $27.2 \pm 4.7$ & $26.0 \pm 5.7$ \\
Waist $(\mathrm{cm})$ & $84.5 \pm 32.1$ & $80.1 \pm 12.8$ \\
Blood glucose $\left(\mathrm{mg} \cdot \mathrm{dL}^{-1}\right)$ & $98.1 \pm 28.5^{*}$ & $94.0 \pm 19.3$ \\
Total cholesterol $\left(\mathrm{mg}^{-1} \mathrm{dL}^{-1}\right)$ & $212.1 \pm 46.2$ & $202.2 \pm 39.2$ \\
SBP/DBP $(\mathrm{mm} \mathrm{Hg})$ & $126^{*} / 81^{*} \pm 13 / 9$ & $119 / 76 \pm 16 / 11$ \\
RHR (bpm) & $68 \pm 13$ & $72 \pm 11$ \\
HR & $176 \pm 16$ & $177 \pm 14$ \\
Risk factors & & \\
Obesity (\%) & 22 & 24 \\
Impaired fasting glucose $(\%)$ & 31 & 26 \\
Dyslipidemia (\%) & $61^{*}$ & 36 \\
Hypertension (\%) & $32^{*}$ & 21 \\
Physical inactivity (\%) & $62^{*}$ & 77 \\
Smoking (\%) & $12^{*}$ & 6
\end{tabular}

Abbreviations: BALL ST, Ball State Adult fitness program Longitudinal Lifestyle STudy (BALL ST) cohort; BMI, body mass index; DBP, diastolic blood pressure; FRIËND, Fitness Registry and the Importance of Exercise National Database; HRmax, maximal heart rate; METs, metabolic equivalents; RHR, resting heart rate; $\mathrm{SBP}$, systolic blood pressure; $\mathrm{VO}_{2 \text { peak, }}$, peak oxygen consumption. Prevalence of obesity, impaired fasting glucose, dyslipidemia, hypertension, and physical inactivity was defined per current accepted atherosclerotic CVD risk factor criteria. ${ }^{29}$

Data are expressed as mean $\pm \mathrm{SD}$ or \%.

$* p \leq 0.05$.

with a higher prevalence of dyslipidemia, impaired fasting glucose, hypertension, physical inactivity, and smoking $(p<0.05)$.

During the follow-up period (17.7 \pm 11.8 years, range: $1.0-$ 45.8 years) 172 participants died ( 132 men, 40 women), with an overall incidence rate of 11.6 deaths per 1000 person years. The mean age difference for the entire cohort between CPX1 and CPX2 was 8.5 years and the mean change in CRF was $-1.8 \mathrm{~mL} \cdot \mathrm{kg}^{-1} \cdot \mathrm{min}^{-1}$. Table 2 provides a comparison of the descriptive characteristics at CPX1 for participants identified as living and deceased at time of follow-up. Overall, at CPX1 participants that died during the follow-up period were older, more likely to be obese, physically inactive, and have dyslipidemia $(p<0.05)$. Additionally, at CPX1 women that died during the follow-up period had a significantly higher prevalence of hypertension, but were less likely to have diabetes, and men were more likely to be smokers than their living counterparts $(p<0.05)$.

Results from the Cox proportional hazard models assessing risk for all-cause, CVD, and cancer mortality according to per unit change in $\mathrm{VO}_{2 \text { peak }}\left(\mathrm{mL} \cdot \mathrm{kg}^{-1} \cdot \mathrm{min}^{-1}\right)$ between CPX1 and CPX2 are shown in Table 3a. Overall, there was an inverse relationship between the change in CRF and risk for all-cause, CVD, and cancer mortality after adjusting for years between CPXs (model 1). After further adjustment for baseline $\mathrm{VO}_{2 \text { peak }}$, age, and sex (model 2), the strength of the association was increased. The inverse association found between the change in CRF and all-cause $(p<0.01)$ and disease-specific mortality $(p<0.05)$ outcomes remained significant in the multivariable adjusted model (model 3 ). Specifically, a $1 \mathrm{~mL} \cdot \mathrm{kg}^{-1} \cdot \mathrm{min}^{-1}$ increase was found to be associated with $11 \%, 15 \%$, and $16 \%$ lower risk of all-cause, CVD, and cancer mortality, respectively $(p<0.001)$. The inverse relationship between the change in CRF expressed as absolute $\mathrm{VO}_{2 \text { peak }}\left(\mathrm{L} \cdot \mathrm{min}^{-1}\right)$ and risk for all-cause, CVD, and cancer mortality was significant $(p<0.05)$ for each model.

The inverse association between change in $\mathrm{VO}_{2 \text { peak }}$ and all-cause mortality was also present for both men and women, when assessed independently, in both models 1 and 2 (Table 3b). Specifically in model 2 , a $1 \mathrm{~mL} \cdot \mathrm{kg}^{-1} \cdot \mathrm{min}^{-1}$ increase was found to be associated with approximately a $10 \%$ and $11 \%$ lower risk of all-cause mortality in men and women, respectively $(p<0.05)$. In model 3 , following multivariable 
Descriptive characteristics at CPX1 of the living and deceased participants within the BALL ST cohort.

\begin{tabular}{|c|c|c|c|c|}
\hline & \multicolumn{2}{|l|}{ Men } & \multicolumn{2}{|l|}{ Women } \\
\hline & Living $(n=420)$ & Deceased $(n=132)$ & Living $(n=241)$ & Deceased $(n=40)$ \\
\hline Age (years) & $42.8 \pm 9.8^{*}$ & $49.3 \pm 8.7$ & $43.1 \pm 10.4^{*}$ & $51.8 \pm 12.0$ \\
\hline RHR (bpm) & $69 \pm 13$ & $64 \pm 16$ & $72 \pm 11$ & $71 \pm 11$ \\
\hline $\mathrm{HR}_{\max }(\mathrm{bpm})$ & $178 \pm 16$ & $173 \pm 16$ & $179 \pm 13^{*}$ & $169 \pm 19$ \\
\hline $\mathrm{VO}_{2 \text { peak }}\left(\mathrm{mL} \cdot \mathrm{kg}^{-1} \cdot \mathrm{min}^{-1}\right)$ & $37.2 \pm 9.6^{*}$ & $34.1 \pm 8.3$ & $28.4 \pm 7.6$ & $27.2 \pm 6.9$ \\
\hline $\mathrm{VO}_{2 \text { peak }}\left(\mathrm{L} \cdot \mathrm{min}^{-1}\right)$ & $3.19 \pm 0.66^{*}$ & $2.80 \pm 0.65$ & $1.92 \pm 0.42$ & $1.83 \pm 0.46$ \\
\hline METs & $10.7 \pm 2.7^{*}$ & $9.7 \pm 2.2$ & $8.1 \pm 2.2$ & $7.8 \pm 2.0$ \\
\hline FRIEND percentile 7,8 & $47 \pm 27$ & $44 \pm 24$ & $54 \pm 25$ & $57 \pm 25$ \\
\hline Weight (kg) & $87.6 \pm 17.2^{*}$ & $83.7 \pm 14.0$ & $69.2 \pm 14.4$ & $68.0 \pm 15.1$ \\
\hline BMI $\left(\mathrm{kg} \cdot \mathrm{m}^{-2}\right)$ & $27.4 \pm 4.8$ & $26.3 \pm 3.9$ & $25.7 \pm 5.6$ & $25.9 \pm 5.8$ \\
\hline Waist $(\mathrm{cm})$ & $94.8 \pm 12.6$ & $93.3 \pm 9.0$ & $79.9 \pm 12.6$ & $79.5 \pm 14.3$ \\
\hline Blood glucose $\left(\mathrm{mg} \cdot \mathrm{dL}^{-1}\right)$ & $97.8 \pm 28.0$ & $95.3 \pm 25.7$ & $93.7 \pm 21.0$ & $94.8 \pm 11.5$ \\
\hline Total cholesterol $\left(\mathrm{mg} \cdot \mathrm{dL}^{-1}\right)$ & $207.3 \pm 45.2^{*}$ & $228.5 \pm 45.7$ & $199.7 \pm 38.9^{*}$ & $217.3 \pm 37.8$ \\
\hline $\mathrm{SBP} / \mathrm{DBP}(\mathrm{mm} \mathrm{Hg})$ & $125^{*} / 81 \pm 13 / 9$ & $129 / 83 \pm 12 / 9$ & $118^{*} / 76^{*} \pm 14 / 10$ & $127 / 80 \pm 19 / 12$ \\
\hline \multicolumn{5}{|l|}{ Risk factors } \\
\hline Obesity (\%) & $25^{*}$ & 12 & $24^{*}$ & 20 \\
\hline Diabetes (\%) & 31 & 35 & $27^{*}$ & 22 \\
\hline Dyslipidemia (\%) & $59^{*}$ & 68 & $34^{*}$ & 45 \\
\hline Hypertension (\%) & 32 & 32 & $20^{*}$ & 30 \\
\hline Physical inactivity (\%) & $59^{*}$ & 68 & $75^{*}$ & 85 \\
\hline Smoking (\%) & $11^{*}$ & 16 & 5 & 6 \\
\hline
\end{tabular}

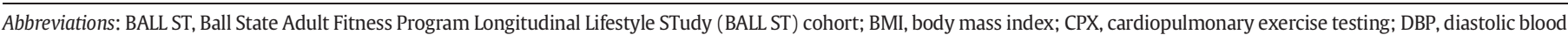

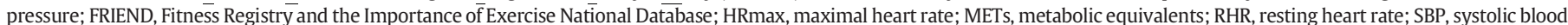

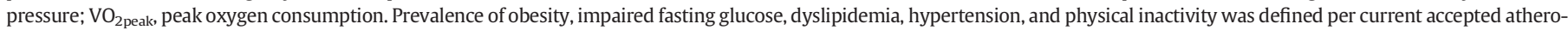
sclerotic CVD risk factor criteria. ${ }^{29}$

Data are expressed as mean $\pm \mathrm{SD}$ or $\%$

* $p \leq 0.05$, living vs. deceased.

adjustment the strength of the association remained for men with a $11 \%$ lower all-cause mortality risk per $1 \mathrm{~mL} \cdot \mathrm{kg}^{-1} \cdot \mathrm{min}^{-1}$ in $\mathrm{VO}_{2 \text { peak }}$. However, in women, the relationship was attenuated and no longer significant in model 3 ( $p=0.29$ ).

To assess if the relationship remained consistent when assessing the change in CRF over a longer period of time between CPXs, Cox models were obtained on a sub-group with $\geq 5$ years between CPX1 and CPX2. The inverse association between the change in CRF and all-cause, CVD, and cancer mortality was also significant in this sub-cohort $(n=491$, 104 deceased) in both model 1 ( $\mathrm{HR}=0.956,95 \% \mathrm{CI}=0.929-0.983$; $\mathrm{HR}=0.938,95 \% \mathrm{CI}=0.890-0.988 ; \mathrm{HR}=0.954,95 \% \mathrm{CI}=0.906-$ 0.998 , respectively) and in model 2 ( $\mathrm{HR}=0.931,95 \% \mathrm{CI}=0.897-$ 0.967; $\mathrm{HR}=0.923,95 \% \mathrm{CI}=0.861-0.990 ; \mathrm{HR}=0.925,95 \% \mathrm{CI}=$ $0.864-0.990$, respectively). Model 3 showed each $1 \mathrm{~mL} \cdot \mathrm{kg}^{-1} \cdot \mathrm{min}^{-1}$ increase in CRF to be significantly associated with 6\% lower risk of all-cause mortality $(p<0.01)$, and to be marginally associated with an $8.7 \%$ and $7.2 \%$ lower risk for CVD $(p=0.09)$ and cancer mortality $(p=0.10)$, respectively.

Results from the Cox proportional hazard model and Wald-chi square test of equality comparing CPX1 CRF to CPX2 CRF as predictors

\section{Table 3a}

Hazard ratios for all-cause, CVD, and cancer mortality outcomes for BALL-ST cohort according to change in $\mathrm{CRF}$, expressed as both $\mathrm{VO}_{2 \text { peak }}$ and METs.

\begin{tabular}{|c|c|c|c|}
\hline Mortality & Hazard Ratio (95\% CI) & $\%$ reduction $/ \mathrm{mL} \cdot \mathrm{kg}^{-1} \cdot \mathrm{min}^{-1}$ & $\%$ reduction/MET \\
\hline \multicolumn{4}{|c|}{ All-cause mortality } \\
\hline Model 1 & $0.923^{*}(0.953-0.972)$ & 7.7 & 27.0 \\
\hline Model 2 & $0.889^{*}(0.873-0.926)$ & 11.1 & 38.9 \\
\hline Model 3 & $0.892^{*}(0.843-0.943)$ & 10.8 & 37.8 \\
\hline \multicolumn{4}{|c|}{ CVD mortality } \\
\hline Model 1 & $0.900^{*}(0.863-0.939)$ & 10.0 & 35.0 \\
\hline Model 2 & $0.886^{*}(0.840-0.935)$ & 11.4 & 39.9 \\
\hline Model 3 & $0.853^{\dagger}(0.750-0.971)$ & 14.7 & 51.5 \\
\hline \multicolumn{4}{|c|}{ Cancer mortality } \\
\hline Model 1 & $0.924^{\dagger}(0.887-0.962)$ & 7.6 & 26.6 \\
\hline Model 2 & $0.894^{*}(0.849-0.942)$ & 10.6 & 27.1 \\
\hline Model 3 & $0.861^{*}(0.774-0.957)$ & 15.9 & 55.7 \\
\hline
\end{tabular}

for all-cause mortality are shown in Table 4. CRF measured at CPX2 was found to be a stronger predictor of all-cause mortality than the CPX1 CRF measurement in the unadjusted model, as well as after adjusting for years between $\mathrm{CPXs}, \mathrm{VO}_{2 \text { peak }}$ measured at $\mathrm{CPX} 1$, age, and sex.

\section{Discussion}

The change in CPX-derived CRF over time in apparently healthy adults was found to be a strong predictor of all-cause, CVD, and cancer mortality. Significant changes in mortality outcomes were seen even with small changes in $\mathrm{CRF}\left(1 \mathrm{~mL} \cdot \mathrm{kg}^{-1} \cdot \mathrm{min}^{-1}\right)$ and were independent of changes in traditional CVD risk factors. These results highlight the importance of improving low CRF or maintaining an adequate CRF level throughout the lifespan for both men and women.

The inverse relationship found in the current study using CPX-CRF revealed a stronger association with mortality compared to past studies that used $\mathrm{CRF}_{\mathrm{e}}$. Overall, the current study found a $37.8 \%$ lower risk in allcause mortality risk with each MET higher change (10.8\% lower risk per $\left.1 \mathrm{~mL} \cdot \mathrm{kg}^{-1} \cdot \mathrm{min}^{-1} ; 1 \mathrm{MET}=3.5 \mathrm{~mL} \cdot \mathrm{kg}^{-1} \cdot \mathrm{min}^{-1}\right)$, and risk reductions of $35.4 \%$ and $27.3 \%$ per 1 MET increase in men and women when assessed independently. To place this change in perspective, each decade of age is associated with $>1$ MET reduction in CRF. Blair et al. studied 9777 men from the Aerobic Center Longitudinal Study (ACLS) cohort who performed two preventative maximal exercise tests that were approximately 5 years apart, using $\mathrm{CRF}_{\mathrm{e}}{ }^{18}$ Results showed a $16 \%$ reduction in all-cause mortality risk per 1 MET improvement. More recently, Shah et al. assessed this relationship in 4872 young adults (54\% women, mean age $24.8 \mathrm{y}$ ) that performed two exercise tests, approximately 7 years after baseline. ${ }^{20}$ After approximately 20 years of follow-up, results showed that for every one minute reduction in exercise time on the modified Balke protocol (each minute on the exercise test is approximately equal to $1 \mathrm{MET}$ ) there was a $21 \%$ increase in all-cause mortality. Although differences in the strength of the association between the current study findings and those from these past studies may result from differences in cohort characteristics, the method used to measure CRF may have also impacted the findings. ${ }^{9}$ 
Table 3b

Hazard ratios for all-cause mortality outcomes for men and women according to change in CRF, expressed as both $\mathrm{VO}_{2 \text { peak }}$ and $\mathrm{METs}$.

\begin{tabular}{|c|c|c|c|}
\hline All-cause mortality & Hazard ratio $(95 \% \mathrm{CI})$ & $\%$ reduction $/ \mathrm{ml} \cdot \mathrm{kg}^{-1} \cdot \mathrm{min}^{-1}$ & \% reduction/MET \\
\hline \multicolumn{4}{|l|}{ Men } \\
\hline Model 1 & $0.934^{*}+(0.911-0.957)$ & 6.6 & 23.1 \\
\hline Model 2 & $0.903^{*}(0.874-0.933)$ & 9.7 & 34.0 \\
\hline Model 3 & $0.899^{*}(0.842-0.960)$ & 10.1 & 35.4 \\
\hline \multicolumn{4}{|l|}{ Women } \\
\hline Model 1 & $0.897^{*}(0.929-0.999)$ & 10.3 & 36.1 \\
\hline Model 2 & $0.887^{*}(0.825-0.953)$ & 11.3 & 39.6 \\
\hline Model 3 & $0.922(0.793-1.072)$ & 7.8 & 27.3 \\
\hline
\end{tabular}

Abbreviations: $\mathrm{CRF}=$ cardiorespiratory fitness; $\mathrm{CVD}=$ cardiovascular disease; $\mathrm{VO}_{2 \text { peak }}=$ peak oxygen consumption.

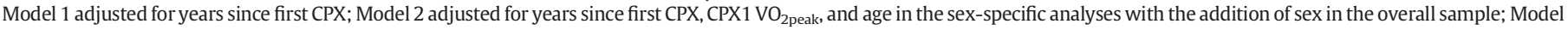

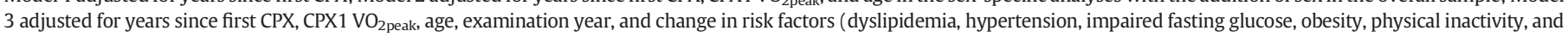
smoking) for the sex-specific analyses with the addition of sex when models were obtained for the overall sample.

$* p \leq 0.01$.

$+p \leq 0.05$.

A common limitation of $\mathrm{CRF}_{\mathrm{e}}$, is the reported estimation error of approximately \pm 1 to 2 METs. ${ }^{9,29,33,34}$ Given that exercise training can result in CRF improvements of this amount, ${ }^{35}$ this error may lead to erroneous interpretation of one's change in CRF level (i.e. fit to fit vs. unfit to fit), limiting the strength of the association. These limitations may be overcome by CPX, which provides a direct, quantitative, and more accurate measure of CRF. ${ }^{22,23,36}$ However, only one other study to date has assessed the relationship between the change in CPX-CRF over time (>1 year) and mortality risk in apparently healthy individuals. ${ }^{15}$ This study assessed middle aged men (42-60 years) from eastern Finland that performed two CPXs using cycle ergometry with 11 years between tests. Results showed each $1 \mathrm{ml} \cdot \mathrm{kg}^{-1} \cdot \mathrm{min}^{-1}$ increase in CPX-CRF was associated with a $10 \%$ lower risk of all-cause mortality after adjusting for baseline $\mathrm{VO}_{2 \text { peak. }}$. The current results showed similar findings, of an $11.1 \%$ and $9.7 \%$ lower risk for all-cause mortality per $1 \mathrm{~mL} \cdot \mathrm{kg}^{-1} \cdot \mathrm{min}^{-1}$ increase in $\mathrm{VO}_{2 \text { peak }}$ in the overall cohort and in men only, after similar model adjustment, respectively. However, CRF is known to be influenced by sex and age..$^{22,36-38}$ We also observed an $11.3 \%$ lower risk for all-cause mortality per $1 \mathrm{~mL} \cdot \mathrm{kg}^{-1} \cdot \mathrm{min}^{-1}$ increase in $\mathrm{VO}_{2 \text { peak }}$ in the women. The wider age distribution, use of treadmill as a mode with CPX, and the inclusion of women in the current cohort, helps to advance our understanding of the influence CPX-CRF has on mortality outcomes across the lifespan.

There was also a significant inverse relationship found between the change in CRF and disease-specific mortality in the current cohort. Each $1 \mathrm{~mL} \cdot \mathrm{kg}^{-1} \cdot \mathrm{min}^{-1}$ increase was associated with $15 \%$ and $16 \%$ lower risk of CVD and cancer mortality, respectively, both corresponding to $>50 \%$ lower risk per $1 \mathrm{MET}$ increase. Lee et al. assessed the change in $\mathrm{CRF}_{\mathrm{e}}$, as related to CVD mortality in a cohort of $\sim 14,000$ men from the ACLS cohort that performed two exercise tests. ${ }^{17}$ Results showed each 1 MET improvement was associated with a $19 \%$ reduction in CVD mortality. Zhang et al. also assessed men of the ACLS cohort, examining the relationship between the change in $\mathrm{CRF}_{\mathrm{e}}$ and cancer mortality. ${ }^{16}$ Results showed a $5 \%$ lower risk of cancer mortality with each 1 MET increase. Discrepancies in the findings between studies may be due to differences in cohort characteristics, the time period between tests, as well as

Table 4

Absolute parameter estimates comparing the relationship between $\mathrm{CPX} 1 \mathrm{VO}_{2 \text { peak }}$ and $\mathrm{CPX} 2 \mathrm{VO}_{2 \text { peak }}$ in the cox model to mortality outcomes with Wald Chi-square test of equality.

\begin{tabular}{llll}
\hline & $\begin{array}{l}\text { Absolute parameter } \\
\text { estimate CPX1 }\end{array}$ & $\begin{array}{l}\text { Absolute parameter } \\
\text { estimate CPX2 }\end{array}$ & $p$ \\
\hline Model 1 & 0.014 & $0.052^{\mathrm{a}}$ & 0.001 \\
Model 2 & 0.006 & $0.029^{\mathrm{a}}$ & 0.001 \\
\hline
\end{tabular}

Abbreviations: $\mathrm{CPX}$, cardiopulmonary exercise testing; $\mathrm{VO}_{2 \text { peak, }}$ peak oxygen consumption.

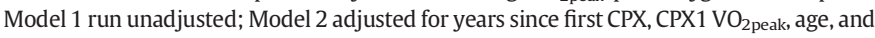
sex.

${ }^{\mathrm{a}}$ Comparison of the coefficients for $\mathrm{CPX} 1 \mathrm{VO}_{2 \text { peak }}$ to $\mathrm{VO}_{2 \text { peak }}$ measured at $\mathrm{CPX} 2$. methodological factors such as the different methods used in determining CRF.

A recent 2016 AHA scientific statement advocated that CRF should be considered a clinical vital sign. ${ }^{9}$ The findings from the current study demonstrate the value of periodic measurement of CPX-CRF as the change in CPX-CRF over time was found to improve mortality risk assessment compared to one-time measure. In a cross-sectional analysis using the current cohort assessing the relationship between baseline CPX-CRF and all-cause mortality, there was an $11.6 \%$ lower risk per MET increment difference, which was similar to the $13 \%$ lower risk of all-cause mortality per MET increment difference reported in a review by Kodama et al. of 33 studies assessing the cross-sectional relationship between CRF and mortality. ${ }^{3,7}$ However, the magnitude of the association between the change in CRF and all-cause mortality was found to be greater than that found using a single measure, with a nearly $27 \%$ lower risk per MET increase between CPX1 and CPX2. The smaller magnitude of the association found in these cross-sectional analyses may be a result of the lack of information on changes in CRF over time, especially since an expected response to identification of low CRF would be to begin or increase exercise training. To further highlight the importance of routine CRF assessment, CRF measures taken at CPX1 and CPX2 were compared as predictors of mortality. The CPX2 CRF was found to be a stronger predictor of all-cause mortality compared with the CPX1 CRF measure.

On average, CRF declines at least 1 MET per decade of age $e^{22,39}$ and the current study suggests that attenuating this decline is associated with reduced risk of mortality. Regular PA can help mitigate this agerelated reduction to preserve an adequate/acceptable CRF level for one's age and sex. PA behavior accounts for approximately $50 \%$ of the variation in CRF and it has been reported that individuals beginning a moderate to vigorous aerobic exercise program can increase their CRF by approximately 1 to 2 METs. ${ }^{8,35,40}$ On the contrary, those that reduce their PA over time can experience lifestyle related declines in CRF, greater than normally experienced due to increasing age. ${ }^{41}$ These changes in PA behavior, influencing changes in CRF may potentially alter mortality risk over time. These results can be seen as encouraging for individuals that have low CRF, as they suggest CRF improvements, achievable through regular PA/exercise, can reduce mortality risk.

\section{Strengths and limitations}

The study used CPX, the gold standard method for measuring CRF, providing an accurate representation of the change in CRF over time. Additionally, the BALL ST cohort consisted of men and women across a wide distribution of age and risk factors. Therefore, the results may be more representative of the population that clinicians see on a regular basis, enhancing utilization in clinical practice. Sex-specific analyses were also performed when assessing all-cause mortality, compared to most studies including both men and women, which have solely 
adjusted for sex in statistical models. This cohort allows for a better understanding of how changes in CPX-CRF may influence prognosis differently in men and women. Finally, the study had an extensive mortality follow-up of 17.7 years, which adds to the knowledge base of the impact changes in CRF across time have on mortality risk.

The limitations of the present study include a $>90 \%$ non-Hispanic white cohort. Future work is needed to confirm these findings in populations from diverse racial and ethnic backgrounds that are known to influence health outcomes. ${ }^{42}$ Additionally, statistical power was reduced for sex-specific analyses when assessing disease-specific mortality, therefore men and women were only analyzed independently when assessing all-cause mortality outcomes. Future studies should assess the association between the change in CRF and CVD and cancerspecific mortality in a large cohort of men and women with greater disease-specific mortality end-points.

\section{Conclusion}

Change in CPX-CRF over time was inversely related to all-cause, CVD, and cancer mortality in a cohort of apparently healthy adults. This relationship was strengthened when accounting for the change in traditional CVD risk factors, further demonstrating the importance of CRF for determining health outcomes. These findings support the clinical value of CPX-CRF and highlight the importance of its routine measurement in clinical practice. Although clinicians should encourage all to participate in regular PA/exercise, as a way to help improve or maintain adequate CRF levels, these findings may be particularly promising to those identified as low fit, as they suggest even small improvements in CRF can have a profoundly positive impact on reducing mortality risk.

\section{Statement of conflict of interest}

L. Kaminsky serves as a Scientific Advisor for ENDO Medical, Inc.

\section{Financial support, funding, grants}

Support for this project was provided, in part, from an American Heart Association Award \#AIREA33930023 (M. Harber, PI).

\section{Acknowledgments}

The authors thank Lynn Witty, MD for her assistance in providing clinical feedback regarding data interpretation and for editorial feedback in the preparation of this manuscript a and Leroy (Bud) Getchell, Ph.D. for his role in developing the Ball State University Adult Fitness Program which is the foundation of BALL ST.

\section{References}

1. Arena R, McNeil A, Sagner M, Lavie CJ. Healthy living: the universal and timeless medicine for healthspan. Prog Cardiovasc Dis 2017;59:419-421.

2. Arena R, Bond S, O'Neill R, et al. Public park spaces as a platform to promote healthy living: introducing a healthpark concept. Prog Cardiovasc Dis 2017;60:152-158.

3. Imboden MT, Harber MP, Whaley MH, Finch WH, Bishop DL, Kaminsky LA. Cardiorespiratory fitness mortality in healthy men and women. J Am Coll Cardiol 2018;72: 2283-2292.

4. Blair SN, Kohl HW, Paffenbarger RS, Clark DG, Cooper KH, Gibbons LW. Physical fitness and all-cause mortality: a prospective study of healthy men and women. JAMA 1989;262:2395-2401.

5. Myers J, Prakash M, Froelicher V, Do D, Partington S, Exercise Capacity Atwood JE. Mortality among men referred for exercise testing. N Engl J Med 2002:346:793-801.

6. Laukkanen JA, Lakka TA, Rauramaa R, et al. Cardiovascular fitness as a predictor of mortality in men. Arch Intern Med 2001;161:825-831.

7. Kodama S, Saito K, Tanaka S, et al. Cardiorespiratory fitness as a quantitative predictor of all-cause mortality and cardiovascular events in healthy men and women: a meta-analysis. JAMA 2009;301:2024-2035.

8. Fletcher GF, Landolfo C, Niebauer J, Ozemek C, Arena R, Lavie CJ. Promoting physical activity and exercise: JACC health promotion series. J Am Coll Cardiol 2018;72:1622-1639.

9. Ross R, Blair SN, Arena R, et al. Importance of assessing cardiorespiratory fitness in clinical practice: a case for fitness as a clinical vital sign. Circulation 2016;134:e653-e699.
10. Lavie CJ, Arena R, Swift DL, et al. Exercise and the cardiovascular system: clinical science and cardiovascular outcomes. Circ Res 2015;117:209-219.

11. Wisloff U, Lavie CJ. Taking physical activity, exercise, and fitness to a higher level. Prog Cardiovasc Dis 2017;60:1-2

12. Carnethon MR, Gidding SS, Nehgme R, Sidney S, Jacobs Jr DR, Liu K. Cardiorespiratory fitness in young adulthood and the development of cardiovascular disease risk factors. JAMA 2003;290:3092-3100.

13. Martin BJ, Arena R, Haykowsky M, et al. Cardiovascular fitness and mortality after contemporary cardiac rehabilitation. Mayo Clin Proc 2013;88:455-463.

14. Sui X, Sarzynski MA, Lee DC, Kokkinos PF. Impact of changes in cardiorespiratory fitness on hypertension, dyslipidemia and survival: an overview of the epidemiological evidence. Prog Cardiovasc Dis 2017;60:56-66.

15. Laukkanen JA, Zaccardi F, Khan H, Kurl S, Jae SY, Rauramaa R. Long-term change in cardiorespiratory fitness and all-cause mortality: a population-based follow-up study. Mayo Clin Proc 2016;91:1183-1188.

16. Zhang P, Sui X, Hand GA, Hebert JR, Blair SN. Association of changes in fitness and body composition with cancer mortality in men. Med Sci Sports Exerc 2014;46: 1366-1374.

17. Lee DC, Sui X, Artero EG, et al. Long-term effects of changes in cardiorespiratory fitness and body mass index on all-cause and cardiovascular disease mortality in men: the aerobics center longitudinal study. Circulation 2011;124:2483-2490.

18. Blair SN, Kohl HW, Barlow CE, Paffenbarger RS, Gibbons LW, Macera CA. Changes in physical fitness and all-cause mortality: a prospective study of healthy and unhealthy men. JAMA 1995;273:1093-1098.

19. Kokkinos P, Myers J, Faselis C, et al. Exercise capacity and mortality in older men: a 20-year follow-up study. Circulation 2010;122:790-797.

20. Shah RV, Murthy VL, Colangelo LA, et al. Association of fitness in young adulthood with survival and cardiovascular risk: the coronary artery risk development in young adults (CARDIA) study. JAMA Intern Med 2016;176:87-95.

21. Erikssen G, Liestol K, Bjornholt J, Thaulow E, Sandvik L, Erikssen J. Changes in physical fitness and changes in mortality. Lancet 1998:352:759-762.

22. Kaminsky LA, Arena R, Myers J. Reference standards for cardiorespiratory fitness measured with cardiopulmonary exercise testing: data from the Fitness registry and the importance of Exercise National Database. Mayo Clin Proc 2015;90:1515-1523.

23. Kaminsky LA, Arena R, Beckie TM, et al. The importance of cardiorespiratory fitness in the United States: the need for a national registry: a policy statement from the American Heart Association. Circulation 2013;127:652-662.

24. Harber MP, Kaminsky LA, Arena R, et al. Impact of cardiorespiratory fitness on allcause and disease-specific mortality: advances since 2009. Prog Cardiovasc Dis 2017;60:11-20.

25. Guazzi M, Arena R, Halle M, Piepoli M, Myers J, Lavie CJ. 2016 focused update: clinical recommendations for cardiopulmonary exercise testing data assessment in specific patient populations. Circulation 2016;133:e694-e711.

26. Whaley MH, Kaminsky LA, Dwyer GB, Getchell LH. Failure of predicted VO2peak to discriminate physical fitness in epidemiological studies. Med Sci Sports Exerc 1995;27:85-91.

27. Whaley MH, Kaminsky LA, Dwyer GB, Getchell LH, Norton JA. Predictors of over- and underachievement of age-predicted maximal heart rate. Med Sci Sports Exerc 1992;24:1173-1179.

28. U.S. Department of health and human services. Physical Activity Guidelines for Americans; 2008.

29. American College of Sports Medicine. ACSM's Guidelines for Exercise Testing and Prescription. 10th ed. Philadelphia, PA: Wolters Kluwer. 2017.

30. Myers J, Forman DE, Balady GJ, et al. Supervision of exercise testing by nonphysicians: a scientific statement from the American Heart Association. Circulation 2014;130: 1014-1027.

31. National Center for Health Statistics. The international classification of diseases. 10th Revision: ICD 10; 1992.

32. National Center for Health Statistics. The international classification of diseases, 9th revision. Clinical Modification; 1978.

33. Myers J. Essentials of Cardiopulmonary Exercise Testing. Champaign, IL: Human Kinetics. 1996.

34. Fletcher GF, Ades PA, Kligfield P, et al. Exercise standards for testing and training: a scientific statement from the american heart association. Circulation 2013;128:873-934.

35. Bouchard C, An P, Rice T, et al. Familial aggregation of VO(2max) response to exercise training: results from the HERITAGE family study. J Appl Physiol 1999;87:1003-1008.

36. Kaminsky LA, Imboden MT, Arena R, Myers J. Reference standards for cardiorespiratory fitness measured with cardiopulmonary exercise testing using cycle ergometry: data from the Fitness registry and the importance of Exercise National Database (FRIEND) registry. Mayo Clin Proc 2017;92:228-233.

37. Kokkinos P, Myers J, Franklin BA, Narayan P, Lavie CJ, Faselis C. Cardiorespiratory fitness and health outcomes: a call to standardize fitness categories. Mayo Clin Proc 2017;92. [in press].

38. Nauman J, Tauschek LC, Kaminsky LA, Nes BM, Wisloff U. Global fitness levels: findings from a web-based surveillance report. Prog Cardiovasc Dis 2017;60:78-88.

39. Aspenes ST, Nilsen TI, Skaug E-A, et al. Peak oxygen uptake and cardiovascular risk factors in 4631 healthy women and men. Med Sci Sports Exerc 2011:43:1465-1473.

40. Skinner JS, Jaskolska A, Krasnoff J, et al. Age, sex, race, initial fitness, and response to training: the HERITAGE family study. J Appl Physiol 2001;90:1770-1776.

41. Neufer PD. The effect of detraining and reduced training on the physiological adaptations to aerobic exercise training. Sports Med 1989;8:302-320.

42. Swift DL, Johannsen NM, Earnest CP, Newton Jr RL, McGee JE, Church TS. Cardiorespiratory fitness exercise training in African Americans. Prog Cardiovasc Dis 2017;60: 96-102. 